\title{
PROBLEMS IN THE TEACHING OF PRACTICAL PHONEMICS
}

\author{
KeNNeth L. Pike \\ University of Michigan \\ Summer Institute of Linguistics
}

$\mathrm{C}^{\mathrm{s}}$

ERTAIN TYPES of students wish to obtain enough training in linguistics to be able to transcribe with adequate symbols a language which hitherto has been unwritten. Ethnologists may want to record names for cultural objects or institutions; travelers may wish to record place names; educators, and especially missionaries, may wish to reduce a language to writing and prepare in it a literature for the natives to read.

These students tend to insist on receiving in the classroom a practical working knowledge of linguistics but to hearken listlessly to the underlying theory and history of the science. For them to continue the course it is not sufficient that the material be practical-it must also appear practical. The information must contribute obviously to their phonetic ability early in the term and furthermore must appeal to their "common sense" for justification of its premises.

In the classes of the Summer Institute of Linguistics, ${ }^{1}$ a school which prepares anthropologists, ethnologists, missionaries, and linguists in the techniques of analyzing hitherto unwritten languages, the practicality of phonetics and phonemics is proved to the students in various ways:

(1) Before any theory is presented as such, two members of the staff give a demonstration of methods of analysis. A speaker of some language unknown to students and staff is asked by way of English to tell the class how he says various items in his language. The staff members write the material on the blackboard in tentative phonetic script and discuss various orthographical difficulties as they arise. Grammatical forms are similarly recorded, analyzed, and discussed. By the time this six-hour demonstration is well under way,

${ }^{1}$ With headquarters in Glendale, California, and with academic sessions on the campus of the University of Oklahoma, at Norman, and branch sessions at Caronport, Saskatchewan, Canada. 
the class has usually turned into an open forum, with students volunteering questions and suggestions.

Since this material represents a very close approximation to the actual situation in which many of them will soon be immersed, the students listen attentively to large amounts of inductively developed theory which they would otherwise not readily accept.

(2) At the end of the summer session, speakers of various languages (mostly American Indians of various tribes) are brought to the campus. Regular classes are suspended, and the students individually attempt initial analysis of a language, under the supervision of the staff. Each year when the initial demonstration has been given (with the statement that the students will be duplicating the methodology at the end of the summer) student morale has been very high. They have passed from demonstration to theory without protest, since they have already seen that the theory is a practical necessity; by the end of the summer they have become impatient to try analysis themselves, and have entered upon it enthusiastically. In summers during which the initial demonstration was omitted or delayed, student morale has proved difficult to maintain, since they have not seen the practicality of the materials early enough to appreciate them.

(3) Classroom procedure and theory is linked as closely as possible to field procedure. Step-by-step analytical techniques are taught in the theory classes in such a way that the student may apply them in that same order, with some success, in his work with an informant at the end of the summer.

Before a theory of orthography formation can be assimilated and practiced, the student needs drill in the analysis, reproduction, and transcription of sounds. Yet many students are loath to try to pronounce sounds strange to them for fear of feeling awkward or appearing queer to their colleagues. Initial drills are necessary, therefore, to reestablish a childlike readiness for mimicry. In the Institute classes the best success in thus establishing readiness to pronounce new sounds has been obtained through reading passages marked for American English intonation, and concomitant attempts to imitate general voice quality through progressive lip rounding, various front and back tongue positions, differences of speed and voice height, and the like, as well as class mimicry of people speaking 
other dialects of English. The student who survives the initial shock of such rough public treatment is ready for rapid learning of individual sounds and possesses general vocal flexibility and linguistic attitudes which at times prove much more important than the attainment of the ability to pronounce certain specific foreign sounds themselves.

The learning of difficult sounds-their recognition, pronunciation, and transcription from dictated forms-needs much drill. Such instruction requires almost individual attention. For a large class this may be difficult to arrange. In the Institute last summer, the beginning class at Norman had approximately 180 students. During the first nine weeks each student had an hour per day of phonetic drill in sections containing four, five, or six students. The thirty to forty-three sections were handled by fifteen to twenty-two instructors; the grammar department and the Canadian branch loaned extra drill masters the first week in order to get this concentration.

This number of thoroughly trained and experienced lecturers in phonetics is difficult to obtain for a single school. Accordingly the Institute brings back from field work many of its younger research members for use on the teaching staff. In order to guarantee uniformity of instruction the phonetic staff assembles each day for a briefing session. The more experienced members of the staff present and explain a lesson plan and check to be sure that each drill master can handle with facility the day's quota of sound types and dictation exercises. The large amount of drill and individual attention contributes to student morale and feeling of progress.

The assumptions which must be mastered before phonemic procedures can be adequately applied are numerous, intricate, and in some important instances still debatable. If the beginning student is presented with many of these, he tends to become uncertain and hopeless. Even the definition of the name of the course-Phonemics - can take half a semester of involved discussions. In order to prevent wasted time and loss of interest it is highly desirable to reduce these phases of the course to a minimum. Thus a "phoneme" is defined as one of the units of sound which the student finds as a result of the procedures given him; this postpones the query, "What is a phoneme?" until the answer is less mysterious or until it seems less important to get an answer in a theoretical form. Also, many 
of the assumptions are, as such, ignored (or put into sections of the text which the beginner does not need to study thoroughly), and the crucial theory is summarized in four basic premises that can be easily remembered even from the start of the course, that can serve as a background for each of the analytical procedures or extended asumptions, and that can be explained and defended more or less successfully in terms of "common sense."

These premises and their explanations are briefly as follows: (1) Sounds tend to slur into their environments. Since sounds are made by physiological movements (of tongue, lips, and so on), and these movements fade into one another, the sounds likewise will reflect the articulatory slurring. If it can be demonstrated that two different sounds, though somewhat similar, could not have been differentiated by their respective environments, then the difference is pertinent to the language and must be symbolized in a practical orthography. So [s] and [ [] are similar, but in "sip" and "ship" the sounds following them are identical and could not have been responsible for causing [s] to slur to [S]; the two must therefore be treated as distinct sounds and be symbolized separately in a phonemic alphabet.

(2) Sound systems, as we know from observation, tend to be somewhat symmetrical. Therefore a lack of symmetry at some point in the system should be regarded with suspicion until the data can be rechecked. The sound [y], for example, does not occur initially in syllables and this nonsymmetrical characteristic gives us pause until we see that $[-n]$ and $[-n]$ must be treated as distinct sounds because of words like "run" and "rung."

(3) Sounds tend to fluctuate. Human beings cannot repeat exactly any series of muscular movements. The articulatory movements are no exception. If any fluctuation proves to be of this or any related nonsignificant variety, it should not be recorded in a practical orthography. Note, for example, the variation between the optional presence and absence of a puff of breath after [t] at the end of a sentence such as "He was hit."

(4) Characteristic sequences of sounds exert pressure on the phonemic interpretation of other sequences. By experience we find that the interpretation of some sequences of sounds is almost never in doubt, but that we must regard certain other sequences with 
suspicion until the available evidence is carefully studied, since their interpretation varies from language to language. For any particular language the interpretation of its doubtful sequences is, in general, assumed to parallel the interpretation of its nondoubtful ones. Thus the aspiration following a [p-] at the beginning of a word in English is assumed to be nonpertinent since $[\mathrm{ph}]$ parallels the occurrence of $[\mathrm{b}-],[\mathrm{n}-]$, etc.

Adequate techniques of phonemic analysis necessitate acceptable work habits. Erratic gathering and weighing of data results in incorrect conclusions-especially so for those procedures in which one must argue from the lack of evidence. The requisite habits may be instilled by requiring the student to work many easy problems by proper methods. Similarly, the student needs good judgment to decide between alternatives when two conclusions are both theoretically valid but not equally advantageous. This judgment can be built up by directed problem solving.

Some of the problems can be chosen from actual language data, provided that the information is not made so profuse that the student needs too much time to handle it, provided he does not become confused by extraneous irregularities, and provided the data are presented in such a way that he can assume for the purpose of that problem that all the data are present so that he can legitimately argue from silence.

Controlled data of this type are not readily procured, since the sounds and the difficulties must be introduced in a graded series with each problem solvable by the premises and procedures presented up to that time. For this reason it proves convenient to utilize hypothetical problems which can be constructed with any desired degree of difficulty, and without distracting complications. ${ }^{2}$

In order to be successful in the field, the student must have developed adequate habits and judgment. In addition, however, he needs an enthusiasm for discovering the unknown. Without a research attitude which sends him with eagerness to a strange unwritten tongue, he is unlikely to progress very far or very satisfactorily in its analysis. Such enthusiasm may be hard to instill

${ }^{2}$ For sample problems see Kenneth L. Pike, Phonemics, A Technique for Reducing Languages to Writing; University of Michigan Publications, Linguistics, Vol. III. University of Michigan Press, Ann Arbor, 1947. 
directly-but it is highly contagious; this personal characteristic the Institute watches in choosing its staff.

For preparing material for publication in the technical journals, however, more than enthusiasm is needed. Hints and patterns of acceptable articles are given to the students of the beginning sessions. During a second summer more attention is paid to this last topic. Rapid reading for acquaintance with the leading articles in the field, further study with informants, and the submitting of tentative phonemic descriptions for seminar discussion help to prepare the student for more thorough technical writing and for a more certain practical application of theory in the field. With proper training he can discover the pertinent units of sound-the phonemes-and record them in a usable orthography. From such research, spring many of the practical goals which the educator or anthropologist may have in view. 